\title{
The Impact of Cold Spells on the Incidence of Infectious Gastroenteritis and Relapse Rates of Inflammatory Bowel Disease: A Retrospective Controlled Observational Study
}

\author{
Christine N. Manser ${ }^{a, b}$ Andrea Kraus ${ }^{c}$ Thomas Frei ${ }^{d} \quad$ Gerhard Rogler $^{a}$ \\ Leonhard Held ${ }^{\mathrm{e}}$ \\ ${ }^{a}$ Division of Gastroenterology and Hepatology, Department of Internal Medicine, University Hospital, Zurich, and \\ ${ }^{b}$ Division of Gastroenterology and Hepatology, Department of Internal Medicine, See-Spital Horgen, Horgen, \\ Switzerland; ' Department of Mathematics and Statistics, Masaryk University, Brno, Czech Republic; \\ ${ }^{d}$ Environmental Research and Consulting, Arni, and ${ }^{e}$ Department of Biostatistics, Epidemiology, Biostatistics and \\ Prevention Institute, University of Zurich, Zurich, Switzerland
}

\section{Keywords}

Climate change $\cdot$ Cold spell $\cdot$ Crohn disease $\cdot$ Inflammatory bowel disease - Ulcerative colitis

\begin{abstract}
Goals: We aimed to assess the impact of very cold days on inflammatory bowel disease (IBD) flares and infectious gastroenteritis (IG). We defined a cold day using the World Meteorological definition of an ice day, which is a day with a maximum temperature below $0^{\circ} \mathrm{C}$. Background: Recently, we have shown that heat waves increase the risk for IG and IBD flares. Study: We retrospectively collected data from 738 IBD and 786 IG patients admitted to the University Hospital of Zurich between 2001 and 2005 and from 506 patients with other noninfectious chronic intestinal inflammations as controls. Climate data were received by the Swiss Federal Office for Meteorology and Climatology. Results: There was no evidence for an increased risk of IBD flares (relative risk, RR = $0.99,95 \%$ confidence interval, $\mathrm{Cl}: 0.72-1.33, p=0.94$ ) or IG flares ( $R R=1.16,95 \% \mathrm{Cl}: 087-1.52, p=0.30)$ on very cold
\end{abstract}

() 2017 S. Karger AG, Basel days. This negative finding was confirmed in alternative formulations with lagged or cumulative (possibly lagged) effects. Conclusion: In this retrospective controlled observational study, no evidence for an increase in hospital admissions due to flares of IBD and IG during cold days was observed. This may be attributed to not relevantly altered bacterial growth conditions during cold days compared to heat waves.

(c) 2017 S. Karger AG, Basel

\section{Introduction}

The health impact of climate change has increasingly attracted attention during the last decades. One major variable of climate is ambient temperature which has steadily increased over the past 150 years. One expression of this warming is the observed increase in the occurrence of heat waves. One recent example is the hot European summer in 2003 with record high temperatures, which was assessed as one of the ten deadliest natural disasters

Christine N. Manse

Division of Gastroenterology and Hepatology

Department of Internal Medicine, See-Spital Horgen, Asylstrasse 19

$\mathrm{CH}-8810$ Horgen (Switzerland)

E-Mail christine.manser@gmx.ch 
in Europe in the last 100 years and the worst in the last 50 years, accounting for up to 70,000 additional deaths in Europe by the United Nations [1-4].

While there have been several reports on mortality following climate changes, only scarce information exists on the impact of temperature on morbidity. The information mainly available is on the impact of heat waves on morbidity. Our own group could reveal an increased risk of inflammatory bowel disease (IBD) flares by $4.6 \%$ and of infectious gastroenteritis (IG) flares by $4.7 \%$ for every additional day within a heat wave period compared to controls [5]. This increase in morbidity and IBD flares has been discussed as being a nonspecific result of physiological stress, i.e. "climate stress." As cold spells also cause some physiological stress to the human body, the question arose whether both extremes of climate fluctuation would have the same effect.

Information on the impact of cold spells on morbidity is very scarce. A study from the US reports an increased risk of $9 \%$ for an ischemic stroke within the 2 days after a $5{ }^{\circ} \mathrm{C}$ decrement in average apparent temperature [6]. However, information on the impact of cold spells on young patients and typical young patients' illnesses, such as IBD is almost completely lacking.

The two major forms of IBD, ulcerative colitis (UC) and Crohn disease (CD), are characterized by a chronic inflammation of the gastrointestinal tract. Besides, both entities show a relapsing course of disease [7]. With regard to disease etiology, genetic predisposition, particularly with reference to $C D$, and environmental factors play an important role [8].

In this retrospective study, we evaluated the influence of cold spells on the incidence of hospital admissions due to IBD. As we have before analyzed the influence of heat waves on IBD flares and IG between 2001 and 2005, we analyzed the same time period. In line with our recent publication, we additionally analyzed the impact of IG, as there have been several reports on the influence of enteric pathogens on the development of IBD [9]. Patients with other noninfectious chronic intestinal inflammations (NII) were used as control group.

\section{Material and Methods}

\section{Study Population}

This study was performed at the University Hospital of Zurich. Patients of any age admitted to the hospital between January 2001 and December 2005 with a final diagnosis of IBD, IG, and NII were included into the study. Patients were selected from an administrative database providing international Classification of Diseases version 10 (ICD-10) [10] codes for final hospital diagnoses as well as information about date of admission and discharge, sex, and age. Codes used to search the database for CD, UC, NII, and IG patients were ICD-10: K50.0-9 (CD), ICD-10: K51.0-9 (UC), ICD-10: K52.0-9 (NII), and ICD-10: A00.0-A09.0 (IG). A total of 2,030 patients met the inclusion criteria and were therefore included. For data validation, we reviewed a random sample of 228 out of all 2,030 patients resulting in only 2 incorrectly encoded samples. We also reviewed the control sample with regard to tourists' hospital admissions due to the region's popularity among tourist. Only 1 out of the 228 reviewed patients was a tourist (for further details, see [5]).

\section{Climate Data}

We used aggregated meteorological data obtained from the meteorological station Zurich-Fluntern. The air temperature data are collected by an automatic weather station located $2 \mathrm{~m}$ above ground level which is in accordance with the recommendations of the World Meteorological Organization.

\section{Cold Day Definitions}

There are two major definitions of the World Meteorological Organization for cold days. A frost day is a day, on which the daily minimum temperature is below $0^{\circ} \mathrm{C}\left(32^{\circ} \mathrm{F}\right)$, whereas an ice day has daily maximum temperature below $0^{\circ} \mathrm{C}$. For the current, study we defined a cold day using the World Meteorological definition of an ice day.

To assess a possible cumulative effect of cold days on hospital admissions, we used the day within a cold day period as a possible predictor for disease incidence. Alternatively, a simple additive effect of a cold day period has also been investigated.

\section{Statistical Analysis}

To compute relative risk estimates for the effect of cold days on daily incidence of IBD, IG, and NII, we used a Poisson regression [11] 95\% profile likelihood confidence intervals (CI) for the relative risk, and associated $p$ values based on the likelihood ratio test statistic have been computed. We adjusted our risk estimates for day-of-the-week effects (with 7 categories, treating public holidays as Sundays), long-term time trends (assumed to be linear), and yearly seasonal patterns (assumed to follow a sine-cosine form) [12]. The analysis is automatically controlled for age, sex, and other patient-specific characteristics, similar to the self-controlled case series method $[13,14]$, because the time-dependent exposure variables are common to all patients. We also analyzed models with lagged effect of a cold day on daily incidence of up to 5 days and alternative cumulative effects. Screening of formulations with additional adjustments for daily average temperature has been done using the BIC criterion. Statistical analyses were performed with the R software [15].

\section{Results}

We detected 117 cold days and 8 periods of $\geq 5$ days in a row during the 2001-2005 study period (Fig. 1). Overall, 2,030 patients with IBD, NII, or IG were admitted to the University Hospital of Zurich during this period. Back-

Cold Spells in IBD 


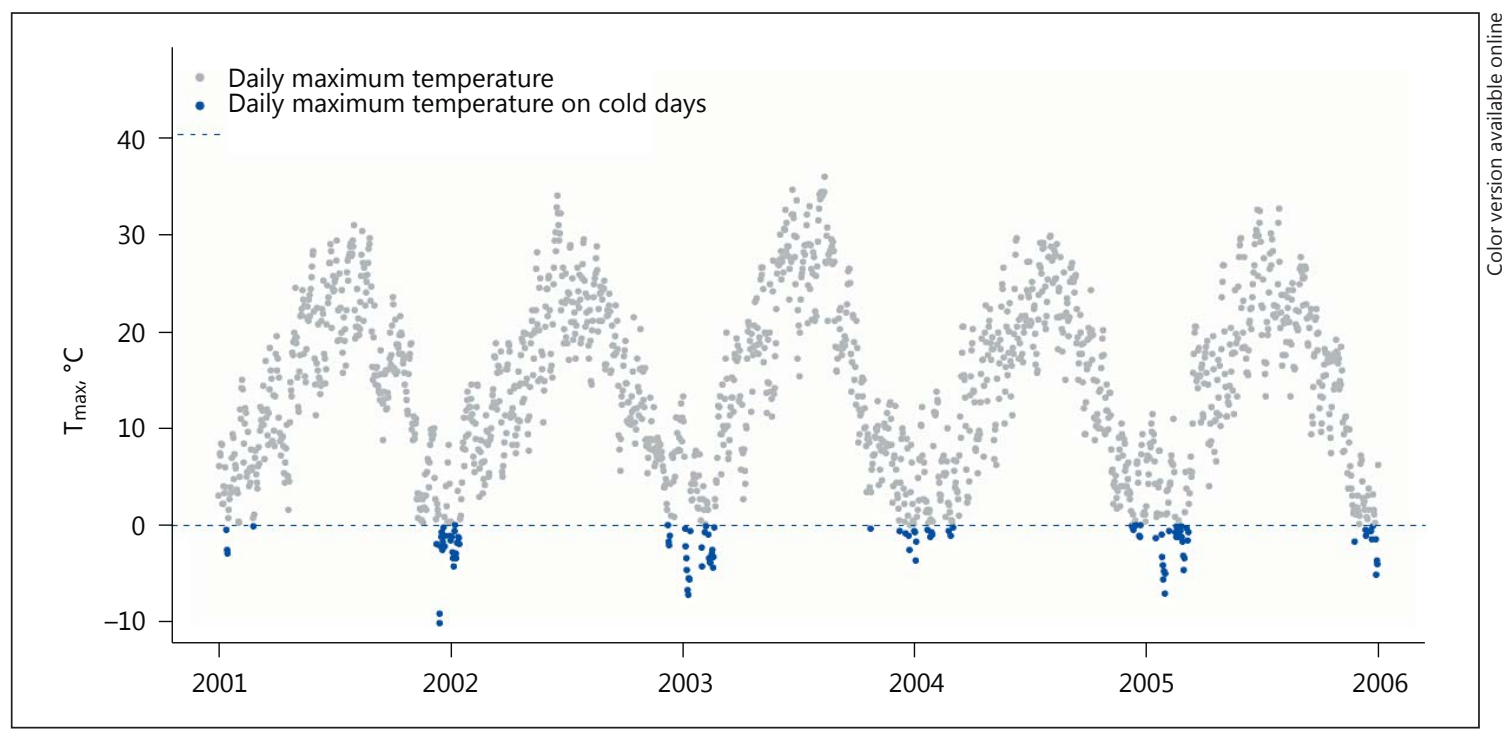

Fig. 1. Daily maximum temperature $\left(\mathrm{T}_{\max }\right)$ in Zurich (measured $2 \mathrm{~m}$ above ground level at the meteorological station Zurich-Fluntern), 01.01.2001-31.12.2005. Days where $\mathrm{T}_{\max }$ does not exceed $0^{\circ} \mathrm{C}$ (dashed blue line), are shown as blue dots.

Table 1. Background information of the study patients

\begin{tabular}{llllll}
\hline & \multicolumn{2}{l}{ IBD } & \multirow{2}{*}{ IG } & NII \\
\cline { 2 - 3 } & UC & CD & & \\
\hline Patients, $n$ & 320 & 418 & & 786 & 506 \\
Female:male ratio & $1: 1.1$ & $1: 0.9$ & & $1: 1$ & $1: 1.2$ \\
Age range, years & $17-92$ & $15-94$ & & $0-96$ & $0-94$ \\
Median age, years & 53 & 44 & & 49 & 55 \\
\hline
\end{tabular}

IBD, inflammatory bowel disease; IG, infectious gastroenteritis; NII, non-infectious intestinal inflammations; UC, ulcerative colitis; CD, Crohn disease.

ground information on the 738 IBD, 786 IG, and 506 NII patients included in the study is shown in Table 1.

Results from several Poisson regression models are shown in Table 2. For each disease group (IBD, IG, NII), the estimated effect of cold days and cold day periods adjusted for day-of-the-week, long-term time trends, and seasonal pattern, is given. Neither for IBD hospital admission, IG, nor the control group of NII, was there evidence for an increase of hospital admissions within a cold day period. This negative finding was confirmed in cumulative models. Alternative formulations with additional adjustments for average temperature did not give any improvement in model fit.
Table 2. Increase in hospital admissions during cold days for IBD, IG, and other NII

\begin{tabular}{llll}
\hline & $\mathrm{RR}$ & $95 \% \mathrm{CI}$ & $p$ value \\
\hline IBD & & & \\
Increase per day & 1.01 & $0.940-1.084$ & 0.70 \\
Increase (additive) & 0.99 & $0.723-1.328$ & 0.94 \\
Increase per day (7-day lag) & 1.00 & $0.924-1.074$ & 0.98 \\
\hline IG & & & \\
Increase per day & 1.04 & $0.972-1.102$ & 0.25 \\
Increase (additive) & 1.16 & $0.873-1.517$ & 0.30 \\
Increase per day (7-day lag) & 1.00 & $0.930-1.070$ & 0.95 \\
\hline NII & & & \\
Increase per day & 0.93 & $0.819-1.031$ & 0.18 \\
Increase (additive) & 0.93 & $0.626-1.345$ & 0.72 \\
Increase per day (7-day lag) & 1.05 & $0.961-1.136$ & 0.25 \\
\hline
\end{tabular}

IBD, inflammatory bowel disease; IG, infectious gastroenteritis; NII, non-infectious intestinal inflammations; RR, relative risk; CI, profile likelihood confidence interval.

\section{Discussion}

We have recently reported a significant impact of heat waves on the incidence of IG and relapse rates of IBD, and this first study on the impact of cold days on IBD or IG does not find an impact of cold days on the incidence of either IG or IBD flares. 
Table 3. Studies on the impact of seasonality on onset and flares in IBD patients

\begin{tabular}{|c|c|c|c|c|c|c|c|}
\hline $\begin{array}{l}\text { First author } \\
\text { [Ref.] }\end{array}$ & $\begin{array}{l}\text { Year of } \\
\text { publication }\end{array}$ & $\begin{array}{l}\text { Time of } \\
\text { inclusion }\end{array}$ & $\begin{array}{l}\text { Pediatric/ } \\
\text { adult }\end{array}$ & $\mathrm{CD} / \mathrm{UC}$ & $\begin{array}{l}\text { Patients, } \\
n\end{array}$ & $\begin{array}{l}\text { Onset/ } \\
\text { flare }\end{array}$ & Results \\
\hline Zeng [16] & 1996 & $1972-1993$ & Adult & $\mathrm{CD}$ & 139 & Flare & $\begin{array}{l}\text { Highest relapse rates in autumn and } \\
\text { winter, lowest in summer }\end{array}$ \\
\hline \multirow[t]{2}{*}{ Moum [17] } & \multirow[t]{2}{*}{1996} & \multirow[t]{2}{*}{$01 / 90-12 / 93$} & \multirow[t]{2}{*}{ Adult } & $\mathrm{CD}$ & 142 & \multirow[t]{2}{*}{ Onset } & No seasonality \\
\hline & & & & $\overline{\mathrm{UC}}$ & 420 & & More onsets in December and January \\
\hline \multirow{2}{*}{$\begin{array}{l}\text { Auslander } \\
{[23]}\end{array}$} & \multirow[t]{2}{*}{2005} & \multirow[t]{2}{*}{$01 / 00-12 / 03$} & \multirow[t]{2}{*}{ Adult } & $\mathrm{CD}$ & 2,708 & \multirow[t]{2}{*}{ Onset } & No seasonality in endoscopic findings \\
\hline & & & & $\overline{\mathrm{UC}}$ & 4,833 & & No seasonality in endoscopic findings \\
\hline \multirow[t]{2}{*}{ Aratari [18] } & \multirow[t]{2}{*}{2006} & \multirow[t]{2}{*}{$06 / 03-05 / 04$} & \multirow[t]{2}{*}{ Adult } & $\mathrm{CD}$ & 150 & \multirow{2}{*}{ Flare } & Higher relapse rates in spring and summer \\
\hline & & & & UC & 203 & & $\begin{array}{l}\text { Trend towards higher relapse rates in } \\
\text { spring and summer }\end{array}$ \\
\hline Bai [19] & 2009 & $01 / 90-12 / 07$ & Adult & $\mathrm{UC}$ & 409 & Flare & More flares in spring and summer \\
\hline Romberg [24] & 2009 & $1991-2002$ & Adult & IBD & 1,264 & Onset & No seasonality \\
\hline \multirow[t]{2}{*}{ Jung [21] } & \multirow[t]{2}{*}{2013} & \multirow[t]{2}{*}{$01 / 03-12 / 10$} & \multirow[t]{2}{*}{ Adult } & $\mathrm{CD}$ & 316 & \multirow[t]{2}{*}{ Flare } & Peak in spring \\
\hline & & & & $\mathrm{UC}$ & 411 & & No seasonality \\
\hline \multirow[t]{2}{*}{ Lee $[20]$} & \multirow[t]{2}{*}{2014} & \multirow[t]{2}{*}{$12 / 08-11 / 10$} & \multirow[t]{2}{*}{ Pediatric } & $\mathrm{CD}$ & 1,325 & \multirow[t]{2}{*}{ Flare } & Trend towards more remission in summer \\
\hline & & & & $\overline{\mathrm{UC}}$ & 587 & & More remission in summer \\
\hline Dharmaraj & 2015 & $07 / 92-07 / 12$ & Pediatric & IBD & 170 & Onset & Highest onset rate in fall \\
\hline$[37]$ & & & & & & Flare & No seasonality \\
\hline \multirow[t]{4}{*}{ Peng [22] } & \multirow[t]{4}{*}{2015} & \multirow[t]{4}{*}{$2003-2011$} & \multirow[t]{4}{*}{ Adult } & $\mathrm{CD}$ & 332 & Onset & Peak in July and August \\
\hline & & & & & & Flare & Peak in July and August \\
\hline & & & & $\mathrm{UC}$ & 569 & Onset & No seasonality \\
\hline & & & & & & Flare & No seasonality \\
\hline $\begin{array}{l}\text { Basaranoglu } \\
{[38]}\end{array}$ & 2015 & & Adult & IBD & 282 & Onset & Peak in winter and early spring \\
\hline
\end{tabular}

IBD, inflammatory bowel disease; UC, ulcerative colitis; CD, Crohn disease.

Seasonal variation regarding onset and clinical course of IBD among adult as well as pediatric IBD patients has been reported in previous studies, as can be seen in Table 3. However, data are conflicting. In 1996, Zeng and Anderson [16] reported on an increased relapse rate during autumn and winter among $139 \mathrm{CD}$ patients. In the same year, Moum et al. [17] observed an increased onset of UC diseases during winter, while there was no seasonality reported regarding onset of CD. In contrast, Zeng and Anderson [16] and Aratari et al. [18] reported on an increased rate of flares among $150 \mathrm{CD}$ patients during spring and summer. The same was observed among UC patients, but without statistical significance. Another study conducted by Bai et al. [19], however, did observe an increase in flares during spring and summer among 409 UC patients. In contrast to this finding, Lee et al. [20] reported on an increase in remission during summer among 587 pediatric UC patients. The same trend was observed among 1,325 pediatric CD patients; however, without significance. Jung et al. [21] as well as Peng at al. [22] reported on a peak of flares in spring. Romberg et al. [24] and Auslander et al. [23] found no seasonality with regard to new onset of IBD. These studies, which show a large diversity of results on the impact of season on the onset or flares of IBD, however, did not investigate possible influencing factors in detail. We believe that one possibility is an influence of temperature changes irrespective of the season. From our point of view, and this is shown by the results of our heat wave as well as the current study, heat waves have a major impact, while cold days do not. 
Table 4. Definitions of cold spells/cold surges in the review article of Ryti et al. [30]

$\mathrm{T}_{\max }<5$ th percentile, duration $\geq 5$ days

Daily $\mathrm{T}_{\text {ave }}<3$ rd percentile, duration $\geq 7$ consecutive days

$\geq 9$ days with daily $\mathrm{T}_{\text {mean }}<3$ rd percentile, of which $\geq 3$ days with daily $\mathrm{T}_{\text {mean }}<1$ st percentile

Fast drop in temperature $\left(>8^{\circ} \mathrm{C}\right.$ temperature drop in $24 \mathrm{~h}$, or $\left.\mathrm{T}_{\min }<10^{\circ} \mathrm{C}\right)$

Daily $\mathrm{T}_{\max }<-3.5^{\circ} \mathrm{C}, \geq 3$ consecutive days

$\geq 9$ days with daily $\mathrm{T}_{\text {ave }}<3$ rd percentile of which $\geq 6$ days with daily $\mathrm{T}_{\text {ave }}<1$ st percentile

$\geq 9$ days with daily $\mathrm{T}_{\min } \leq-5^{\circ} \mathrm{C}$, of which $\geq 6$ days with daily $\mathrm{T}_{\min } \leq 10^{\circ} \mathrm{C}$

Coldest weeks of the study period (average of weekly $\mathrm{T}_{\max }<5^{\circ} \mathrm{C}$ ), duration: 7 consecutive days

We have learned from investigations on the impact of cold days on mortality rather than morbidity that particularly respiratory and cardiovascular diseases are influenced by cold days [25-29]. This is why we have found no comparable studies to our study despite an intensive literature search. A very recent review and meta-analysis on cold spells and adverse health effects mainly reported on cardiovascular and respiratory diseases, although the used search terms did not include preselected diseases but were mainly based on different expressions for cold spells [30]. This study concluded that cold spells are associated with increased mortality from cardiovascular (summary rate ratio [SRR] 1.11; 95\% CI: 1.03-1.19) and respiratory (SRR 1.21; 95\% CI: 0.97-1.51) diseases. However, the authors stress that the substantial heterogeneity among the studies makes comparison and interpretation of results difficult [30].

Interestingly, while the association of heat and mortality was reported to occur within days, the impact of cold days on mortality often appears with a longer lag $[26,31]$. Moreover, the observed time lags seem to differ depending on the involved organs [26]. While cardiovascular diseases peak within few days, a lag of up to 2 weeks is observed in respiratory diseases [26].

Altered environmental bacterial growth conditions are one major hypothesis regarding the observed increase in the number of IBD flares during heat waves [5]. This is mainly due to the knowledge that genetic susceptibility factors for the pathogenesis of IBD are mainly located in genes/proteins of the innate immune response dealing with our intestinal microbiota [32]. As we now hypothesize that environmental bacterial growth conditions do not change during cold days to the same extent as they do during a heat wave, this also explains why we did not observe an impact of cold days on the incidence of IBD flares. One additional point underlining this hypothesis is the fact that in Switzerland heating is generally available, while air conditioning during heat periods is not.
Based on our published data on heat waves, it was speculated that the increased risk of IBD flares might just be due to stress during adaptation to the climate condition. However, cold days representing a climate fluctuation to the other extreme also require physiological adaptation and subsequently cause stress to the body. Our data provide evidence that the observed increase in IBD flares caused by heat waves is not simply due to adaptation stress for the body.

There are a number of limitations to our study. First, there is a risk of misclassification of cases regarding ICD10 codes due to the database origin of the used data. However, about $10 \%$ of patients' charts were reviewed with a rate of misclassified cases of less than $1 \%$. Second, there is also a potential risk of misclassification of control group cases, which might need a classification as IBD or IG. Again, we reviewed almost $25 \%$ of the cases included in our analysis and did not find evidence for misclassification. Third, there is a potential risk of confounding bias as we were not able to control for all potential confounders, although we controlled for some of them, such as age and gender. One potential confounder is smoking. During climate fluctuations, smoking habits might change. Regarding IBD, we know that smoking does have an impact on the course of disease and on the composition of the bacterial flora [33]. Therefore, changes in smoking habits due to changes in temperature influence flares in IBD patients. Furthermore, we were not able to adjust for other time-dependent exposure variables, e.g. humidity. Fourth, we do not know if patients with mild flares might have forgone visiting their treating physicians or emergency departments due to a cold spell. This might be a confounder not included in our analysis. Fifth, contrary to the definition of a heat wave, there is no existing clear definition of a cold spell or cold surge, which mainly results in many different definitions of cold spells among studies on this issue [30]. In the review of Ryti et al. [30], among the 9 included studies, there were only 2 studies 
using the same definition of a cold spell, which was a fast drop in temperature of $>8^{\circ} \mathrm{C}$ in $24 \mathrm{~h}$ or $\mathrm{T}_{\min }<10^{\circ} \mathrm{C}$ [30, $34,35]$. The two major definitions for cold days used by the World Meteorological Organization were not used even once among the included studies. The definitions used are shown in Table 4. Due to the different duration of cold spell definitions as well as different relation to percentiles or absolute temperatures, a valid comparison of results and studies is almost impossible. Finally, the CI for the cumulative effects of cold day periods reported in $\mathrm{Ta}$ ble 2 are wider than those for heat waves [5]. This loss in precision is caused by the fact that cold day periods in Zurich are substantially shorter than heat wave periods. To renounce a loss of statistical power of the analysis, we therefore did not do a subgroup analysis differentiating $\mathrm{CD}$ from UC. However, the CI for the additive effect have nearly the same precision as the corresponding effects for heat waves, but show no evidence for an additive effect of cold days on disease incidence.

Although cold spells do not seem to have an impact on the incidence of IG or IBD flares, the results of our study greatly contribute to the understanding of possible pathomechanisms. In a recent publication, our group reported on an association between high-altitude journeys and flights and an increased risk of IBD flares [36]. We hypothesized that the increase in flares among those patients who went on high-altitude journeys or flights might mainly be due to hypoxia which is known to induce in- flammation. Critics, however, noted that also changes in temperature might play a significant role. The data of the current study, however, do not prove a significant impact of cold temperature on IBD flares. Therefore, our hypothesis of the hypoxia pathomechanism gains is supported.

\section{Disclosure Statement}

The authors declare that there have no conflicts of interest.

\section{Funding Sources}

This study was supported by a research grant from the Swiss National Science Foundation (3347CO-108792) to G.R.

\section{Author Contributions}

All authors have made substantial contributions to all of the following: (1) the conception and design of the study, or acquisition of data, or analysis and interpretation of data, (2) drafting the article or revising it critically for important intellectual content, (3) final approval of the version to be submitted.

Christine N. Manser: data collection, data interpretation, literature search, writing, final approval. Andrea Kraus: data analysis, data interpretation, figures, writing, final approval. Gerhard Rogler: study design, data interpretation, writing, final approval. Thomas Frei: study design, data interpretation, writing, final approval. Leonhard Held: study design, data analysis, data interpretation, figures, writing, final approval.

\section{References}

1 Grize L, Huss A, Thommen O, Schindler C, Braun-Fahrlander C: Heat wave 2003 and mortality in Switzerland. Swiss Med Wkly 2005; 135:200-205.

2 Robine JM, Cheung SL, Le Roy S, Van Oyen H, Griffiths C, Michel JP, Herrmann FR: Death toll exceeded 70,000 in Europe during the summer of 2003. C R Biol 2008;331:171178.

3 Schar C, Vidale PL, Luthi D, Frei C, Haberli C, Liniger MA, Appenzeller C: The role of increasing temperature variability in European summer heatwaves. Nature 2004;427:332336.

4 United Nations Environment Programme: Impact of summer 2003 heat wave in Europe. Environ Alert Bull 2004;2.

5 Manser CN, Paul M, Rogler G, Held L, Frei T: Heat waves, incidence of infectious gastroenteritis, and relapse rates of inflammatory bowel disease: a retrospective controlled observational study. Am J Gastroenterol 2013;108: 1480-1485.
6 Mostofsky E, Wilker EH, Schwartz J, Zanobetti A, Gold DR, Wellenius GA, Mittleman MA: Short-term changes in ambient temperature and risk of ischemic stroke. Cerebrovasc Dis Extra 2014;4:9-18.

7 Xavier RJ, Podolsky DK: Unravelling the pathogenesis of inflammatory bowel disease. Nature 2007;448:427-434.

8 Rogler G: Update in inflammatory bowel disease pathogenesis. Curr Opin Gastroenterol 2004;20:311-317.

9 Sonnenberg A: Seasonal variation of enteric infections and inflammatory bowel disease. Inflamm Bowel Dis 2008;14:955-959.

10 World Health Organization: ICD-10: International Statistical Classification of Diseases and Related Health Problems. Geneva, World Health Organization, 1992.

11 Kuhn L, Davidson LL, Durkin MS: Use of Poisson regression and time series analysis for detecting changes over time in rates of child injury following a prevention program. Am J Epidemiol 1994;140:943-955.
12 Diggle PJ: Time Series: A Biostatistical Introduction. Oxford, Oxford University Press, 1990.

13 Whitaker HJ, Farrington CP, Spiessens B, Musonda P: Tutorial in biostatistics: the selfcontrolled case series method. Stat Med 2006; 25:1768-1797.

14 Whitaker HJ, Hocine MN, Farrington CP: On case-crossover methods for environmental time series data. Environmetrics 2007;18: 157-171.

15 R Development Core Team: R: A Language and Environment for Statistical Computing. Vienna, R Foundation for Statistical Computing, 2010.

16 Zeng L, Anderson FH: Seasonal change in the exacerbations of Crohn's disease. Scand J Gastroenterol 1996;31:79-82.

17 Moum B, Aadland E, Ekbom A, Vatn MH: Seasonal variations in the onset of ulcerative colitis. Gut 1996;38:376-378. 
18 Aratari A, Papi C, Galletti B, Angelucci E, Viscido A, D’Ovidio V, Ciaco A, Abdullahi M, Caprilli R: Seasonal variations in onset of symptoms in Crohn's disease. Dig Liver Dis 2006;38:319-323.

19 Bai A, Guo Y, Shen Y, Xie Y, Zhu X, Lu N: Seasonality in flares and months of births of patients with ulcerative colitis in a Chinese population. Dig Dis Sci 2009;54:1094-1098.

20 Lee GJ, Dotson JL, Kappelman MD, King E, Pratt JM, Colletti RB, Bistrick S, Burkam JL, Crandall WV, ImproveCareNow Network: Seasonality and pediatric inflammatory bowel disease. J Pediatr Gastroenterol Nutr 2014; 59:25-28.

21 Jung YS, Song CS, Kim ER, Park DI, Kim YH, Cha JM, Kim JH, Lee SH, Eun CS, Han DS: Seasonal variation in months of birth and symptom flares in Korean patients with inflammatory bowel disease. Gut Liver 2013;7: 661-667.

22 Peng JC, Ran ZH, Shen J: Seasonal variation in onset and relapse of IBD and a model to predict the frequency of onset, relapse, and severity of IBD based on artificial neural network. Int J Colorect Dis 2015;30:1267-1273.

23 Auslander JN, Lieberman DA, Sonnenberg A: Lack of seasonal variation in the endoscopic diagnoses of Crohn's disease and ulcerative colitis. Am J Gastroenterol 2005;100:22332238.

24 Romberg-Camps MJ, Hesselink-van de Kruijs MA, Schouten LJ, Dagnelie PC, Limonard CB, Kester AD, Bos LP, Goedhard J, Hameeteman WH, Wolters FL, Russel MG, Stockbrugger RW: Inflammatory bowel dis- ease in south Limburg (the Netherlands) 1991-2002: incidence, diagnostic delay, and seasonal variations in onset of symptoms. J Crohns Colitis 2009;3:115-124.

25 Analitis A, Katsouyanni K, Biggeri A, Baccini M, Forsberg B, Bisanti L, Kirchmayer U, Ballester F, Cadum E, Goodman PG, Hojs A, Sunyer J, Tiittanen P, Michelozzi P: Effects of cold weather on mortality: results from $15 \mathrm{Eu}$ ropean cities within the PHEWE project. Am J Epidemiol 2008;168:1397-1408.

26 de'Donato FK, Leone M, Noce D, Davoli M, Michelozzi P: The impact of the February 2012 cold spell on health in Italy using surveillance data. PLoS One 2013;8:e61720.

27 Huynen MM, Martens P, Schram D, Weijenberg MP, Kunst AE: The impact of heat waves and cold spells on mortality rates in the Dutch population. Environ Health Perspect 2001; 109:463-470.

28 Kysely J, Pokorna L, Kyncl J, Kriz B: Excess cardiovascular mortality associated with cold spells in the Czech Republic. BMC Public Health 2009;9:19.

29 Ye X, Wolff R, Yu W, Vaneckova P, Pan X, Tong S: Ambient temperature and morbidity: a review of epidemiological evidence. Environ Health Perspect 2012;120:19-28.

30 Ryti NR, Guo Y, Jaakkola JJ: Global association of cold spells and adverse health effects: a systematic review and meta-analysis. Environ Health Perspect 2016;124:12-22.

31 Son JY, Bell ML, Lee JT: The impact of heat, cold, and heat waves on hospital admissions in eight cities in Korea. Int J Biometeorol 2014;58:1893-1903.
32 Scharl M, Rogler G: Microbial sensing by the intestinal epithelium in the pathogenesis of inflammatory bowel disease. Int J Inflam 2010;2010:671258.

33 Biedermann L, Brulisauer K, Zeitz J, Frei P, Scharl M, Vavricka SR, Fried M, Loessner MJ, Rogler G, Schuppler M: Smoking cessation alters intestinal microbiota: Insights from quantitative investigations on human fecal samples using fish. Inflamm Bowel Dis 2014; 20:1496-1501.

34 Chen VY, Wu PC, Yang TC, Su HJ: Examining non-stationary effects of social determinants on cardiovascular mortality after cold surges in Taiwan. Sci Total Environ 2010;408: 2042-2049.

35 Yang TC, Wu PC, Chen VY, Su HJ: Cold surge: a sudden and spatially varying threat to health? Sci Total Environ 2009;407:34213424.

36 Vavricka SR, Rogler G, Maetzler S, Misselwitz B, Safroneeva E, Frei P, Manser CN, Biedermann L, Fried M, Higgins P, Wojtal KA, Schoepfer AM: High altitude journeys and flights are associated with an increased risk of flares in inflammatory bowel disease patients. J Crohns Colitis 2014;8:191-199.

37 Dharmaraj R, Jaber A, Arora R, Hagglund K, Lyons H: Seasonal variations in onset and exacerbation of inflammatory bowel diseases in children. BMC Res Notes 2015;8:696.

38 Basaranoglu M, Sayilir A, Demirbag AE, Mathew S, Ala A, Senturk H: Seasonal clustering in inflammatory bowel disease: a single centre experience. Expert Rev Gastroenterol Hepatol 2015;9:877-881. 